\title{
Future challenges in psychiatry from the reflections of a quinquagenarian
}

\begin{abstract}
'Are patients any better off now compared with the Eighties? I was lamenting to a junior specialist colleague that, 26 years down the line in psychiatry, I could not honestly answer 'yes.' We have a profusion of papers, a plethora of brain images, and an abundance of new knowledge (soon to be followed by rafts of new diagnoses, I fear), but that's of little succour to those bedevilled by schizophrenia. Haloperidol has been swapped for olanzapine; overweight vasculopaths now out-shadow the rigid and tremulous, and 1 in 3 remain psychotic, whatever we prescribe.
\end{abstract}

And yet this apparent mid-career gloom is at odds with the delight I've had pondering the unknowns of psychiatry - psychopathology and phenomenology are among its real mysteries - and the pleasure of relieving burden with often simple interventions. All in the context of profound socio-political change. In summary, being a psychiatrist in South Africa over the past 3 decades has been a remarkable privilege.

'Well, then challenge us,'was her retort.'Point out the pitfalls, set us the next generation - goals. So we don't make the same mistakes ... This is my humble 10-point offering.

\section{Guard against the appropriation of psychiatry in general}

We need to remain ever vigilant of appropriation of the field of psychiatry - the understanding, detection and treatment of mental illness - by agents of social control, in whatever form they come: politicians, employers, insurers, lawyers, the media and big pharma. The basic tenet of R D Laing's anti-psychiatry was that psychiatry as a movement allowed itself, often unwittingly, to be commandeered by agents of social control in general, and governments (which need homogenised conformity of behaviour) in particular. His hypothesis is as fresh, and chilling, now as then.

\section{Beware of political co-option in particular}

My largely non-interventionist 'we should stick to our knitting' (as medical specialists) position inflames critics who promote advocacy and social agency in the belief of using psychiatry to create a better life for all. But there is a very fine line between using and being used, especially by politicians, masters of the art of social re-arrangement There are certainly opportunities to influence the social order to improve the lot of patients. I recall the horror in the eyes of oldorder politicos who a colleague and I effectively 'trapped' in the disgraceful communal showers of Valkenberg Hospital's black male lock-up ward in the late 1980s, and the improvements that followed. And my first act as a consultant in 1991 was to integrate its racially segregated female closed wards. But it's much like maintaining the boundaries in psychotherapy: if you aren't vigilant of the process, you can end up under a bus without even realising you've stepped into the street.

\section{We're medical specialists, not human resource practitioners}

The new social order in South Africa brought with it markedly altered work places in the 1990s, and a platoon of people - particularly government employees - who wished to prematurely exit their salaried employment without a material loss of corporate benefits. Simultaneously, new labour legislation made it more difficult for the employer to discharge workers, and pension funds have a fiduciary duty to uphold. Answer? The Medical Board! It is beyond even remote possibility that the sudden post-1994 epidemics of posttraumatic stress disorder and major depressive disorder in certain public service sectors, and in delimited geographical regions, were purely coincidental. Having performed several thousand independent opinions for employers, health-risk managers and insurers over the past 15 years, I remain dumb-struck at the ease with which some colleagues have launched themselves outside of their scope of practice (and expertise) to make occupational, legal and moral pronouncements regarding human resource issues and 'entitlement' to premature medical retirement. We certainly have a role in advocating for our patients in the workplace, but human resource and legal matters are best left to their practitioners.

\section{Big pharma ... be afraid, be very afraid ...}

The pharmaceutical industry is crucial to any notion of healthcare. It researches and develops new treatments at great (and risky) cost, it educates, and is a powerful force in the economy. However, it exists primarily to generate a return on the investment of its shareholders, which it is - like any other legitimate business - rightly entitled to do. Patients, practitioners and big pharma all need each other. Our responsibility though, is to be aware of how powerful marketing practices - not all overt - influence our prescribing, and potentially drive up health care costs, ultimately borne by patients.

Whether it's via online 'disease awareness programmes', industryfunded continuing medical education meetings, off-label marketing (mostly highly subtle, as it's illegal) or the influence of key opinion leaders (KOLs), not all is always as it appears to be. I know. I was once a KOL. I wish I'd known at the time ... I frequently flew to Europe in the pointy end of the aeroplane to attend 'advisory board meetings' dressed up as consultative fora for mental healthcare delivery, staying in rather nice hotels and being paid in US dollars 'for my time.' And I thought that they really were collaborative research endeavours until I realised that I was being influenced to influence 
the prescribing behaviour of others. When I came upon an article in a less well-known journal that uncovered deliberate, covert, nearmanualised strategies to manipulate KOLs to grow market share - to which the company implicated had no coherent response - I drew the line, and withdrew.

\section{Diagnostic inflation and the medicalisation of life}

In the USA 1840 census, there were 2 categories of mental illhealth: idiocy and insanity. By the 1880 population count, this had expanded to 7, including dipsomania and epilepsy. Come May 2013, the Diagnostic \& Statistical Manual of Mental Disorders $5^{\text {th }}$ edition (DSM V) is certain to deliver loads of 'new' mental illnesses. USA estimates of attention deficit hyperactivity disorder (ADHD) trebled from 3\% in 1994 to 9.5\% in 2010. Prescribed stimulant use in American children doubled from 2.4\% in 1996 to 4.8\% in 2007, and 'adult ADHD' has enjoyed a similar trajectory. Is this all explicable by uncovering 'missed cases'alone? Methinks not. Shyness has become 'social anxiety disorder', bereavement is soon to be easily called 'major depressive disorder', and even exotica such as hebephilia may get a look in. The next generation of psychiatrists will need to carefully monitor the impact of the new edition of DSM, and guard against the growing medicalisation of life.

\section{Reverse the replacement of clinical acumen by the rating scale}

I learnt the clinical method of psychiatry on the coat tails of experienced - even crusty - old-timers - men and women who spent time with patients, and turned history-gathering and the mental state examination into an art form. In the interim, rating scales have galloped out of the research laboratory into clinical practice rooms as an apparent substitute for eliciting the symptoms and signs of a mental illness to make a diagnosis. Young colleagues often don't see the need to build a case for a diagnosis or to justify it, other than a score on a rating scale.

In the same vein, Andreasen has suggested that in search of reliability and validity in diagnostic manuals, we've lost interest in descriptive psychopathology and phenomenology. And perhaps, as a result, we miss the patient's actual experience. If the new generation of psychiatrists hasn't read Fish's Clinical Psychopathology, the 2007 third edition is available on www.amazon.com ...

\section{Diagnostic rigour, not diagnostic dogmatism}

In tandem with the rise of the rating scale, is a disturbing trend that, seemingly, there is no need to gather and set out the basis for a particular diagnosis; it exists in an individual because a psychiatrist says so. And when one asks for such a basis, in clinical practice, reports, arbitration chambers or the law courts, the response is all too often narcissistic affront rather than clinical substance.
By the same token, diagnoses can only ever be cross-sectional assessments, informed by the past and hopefully predicting the future, but essentially rooted in the present. And, the clinical picture changes. I recall my delight, as a consultant in charge of the PsychoGeriatric Service at Valkenberg Hospital in the late 1990s, revising diagnoses confidently made by my esteemed Professors decades before. Armed with so much more history, it was easy... Thus, while we should make diagnoses with rigour, we should always keep an open mind - psychiatric conditions can take time to fully declare themselves.

\section{Research is not the exclusive preserve of the Professors}

Or, indeed, their sole responsibility. As research funding becomes scarce, projects more complex and the logistics of research endeavour more onerous, I sense a dichotomy that has developed since I first performed a mental state examination: one is either an academic, or not. Bright ideas - clinical epiphanies - are not limited to university laboratories and, if one has the basic intellect and resilience to qualify as a specialist, one has the wherewithal to think creatively, and the responsibility to society to do so.

\section{Research can be simple, and new findings may be'the elephant in the room'}

Many of the early discoveries in clinical psychiatry were made by observant practitioners, those with open minds who noted something new, or trends, or unexpected outcomes. As we beaver away in clinical practice, toiling in overcrowded clinics, oiling the revolving door of hospital wards or battling medical scheme administrators, we lose sight of the blue sky. Or the obvious new finding in the room, right next to us. We must continue to make space to think, to reflect on - indeed, to enjoy - the mysteries of psychiatry.

\section{Honesty and integrity}

Until such time that we discover reliable, practical and accessible biomarkers of psychiatric disease, and have objective, quantitative evidence for the existence of mental ill-health conditions in an individual, psychiatry will remain at the confluence of art and science, and its bases and opinions subject to personal opinion, as well as professional criticism. The only response in such a context is to act with honesty and integrity. As someone once said: 'Ethics is what you do when nobody is watching'.

\author{
David Swingler \\ Head of Psychiatry (Clinical Department) \\ 2 Military Hospital \\ Wynberg \\ swingler@telkomsa.net
}

SAfr J Psych 2012;18(3):76-77. DOI:10.7196/SAJP.382 